\title{
Comparison of the general health level between the nurses working in the hospitals of Kurdistan University of Medical Sciences and Social Security Hospital in 2018-2019
}

\begin{abstract}
Ahdieh Parhizkar ${ }^{1}$
1. M.Sc in Nursing, Department of Community Health Nursing, Faculty of Nursing and Midwifery, Clinical Care Research Center, Research Institute for Health Development, Kurdistan University of Medical Sciences, Sanandaj, Iran., (Corresponding Author), Tel:087-33664664,E-mail: parhizkar_ahdieh@yahoo.com, ORCID ID: 0000-0002-9365-5262
\end{abstract}

\begin{abstract}
Background and Aim: Long time working with seriously ill patients and handling protective role for the patients with specific diseases makes nurses susceptible to various types of physical disorders, which can lead to mood disorders, social isolation, fatigue, anger, depression and anxiety. The aim of this study was to compare the general health level of nurses working in educational hospitals of Kurdistan University of Medical Sciences and Social Security Hospital in 2018-2019.

Materials and Methods: This descriptive-analytical study included 400 nurses working in Kurdistan University of Medical Sciences (300 nurses) and Social Security Hospital (100 nurses) in 2018. Data collection tool was a general health questionnaire which was completed after interview with the participants. Using SPSS software, data were analyzed by t-test and chi-square. $\mathrm{P}$ value less than 0.05 was considered significant.

Results: The results showed that nurses of the University of Medical Sciences had a lower level of physical health and social relations and a higher level of health in regard to anxiety and sleep disorder in comparison to the Social Security Hospital nurses $(p=0.01)$. However, there was no statistically significant differences in suicidal desire and depression between the nurses in the 2 hospital $(\mathrm{p}=0.06)$. There was also a significant relationship between the scores of general health level of the nurses at the University of Medical Sciences and Social Security Hospitals $(\mathrm{p}=0.001)$, indicating that Social Security Hospital nurses had better general health compared to the nurses at medical university hospitals.

Conclusions: Considering the results of this study, nurses working at at medical university hospitals and Social Security Hospital are at risk of health problems which can result in low quality nursing care and low health level in the community. Therefore proper programs are required to improve nurses' health level which can lead to improvement of the health level of the community.
\end{abstract}

Keywords: Health, Job stress, Health dimensions, Nurses

Received: July 14, 2019

Accepted: Jan 10, 2019

How to cite the article: Ahdieh Parhizkar. Comparative Study of the level of General Health of Nurses Working in Educational Hospitals of Kurdistan University of Medical Sciences and Social Security in 2018. SJKU. 2020;25(3):87-98.

Copyright (C) 2018 the Author (s). Published by Kurdistan University of Medical Sciences. This is an open access article distributed under the terms of the Creative Commons Attribution-Non Commercial License 4.0 (CCBYNC), where it is permissible to download, share, remix, transform, and buildup the work provided it is properly cited. The work cannot be used commercially without permission from the journal 


\section{بررسى مقايسهاى سطح سلامت عمومى يرستاران شاغل در بيمارستانهاى آموزشى دانشكاه

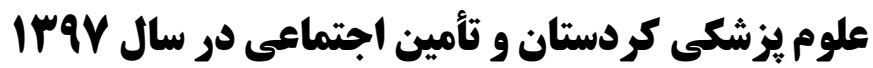

عهديه ير هيز كار'

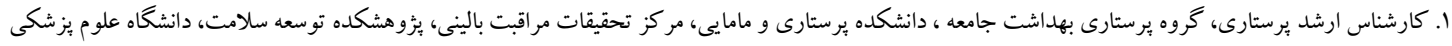

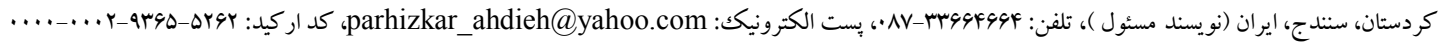

جكيده زمينه و هدف: كار طولانى با بيماران بدحال، و ايفاى نقش حمايتى بيماران خاص، يرستاران را مستعد ابتلا به انواع اختلالات

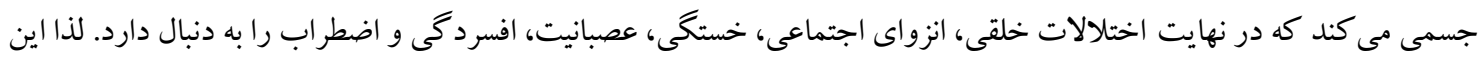

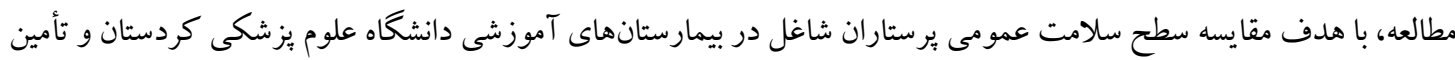

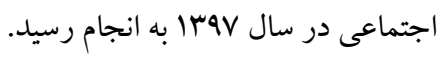

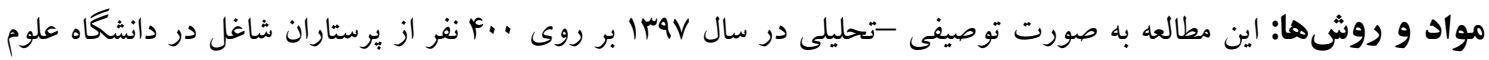

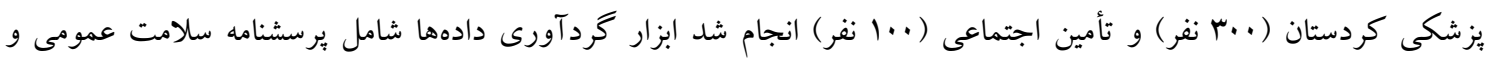

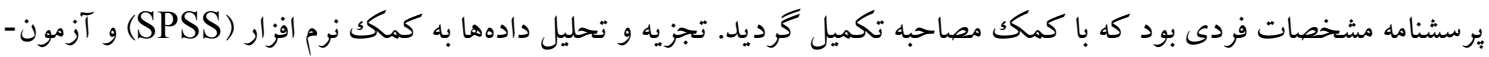

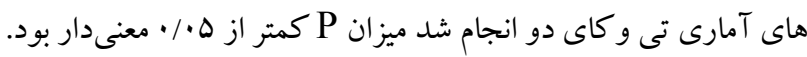

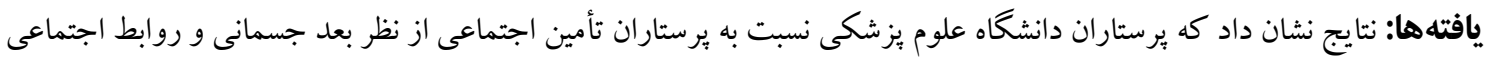
از سلامت پايين ترى برخوردار بودند و در بعد اضطراب و اختلال خواب نسبت به يرستاران تأمين اجتماعى از سلامت بالاترى

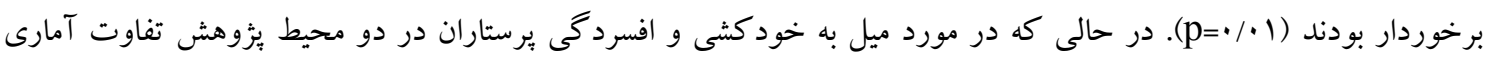

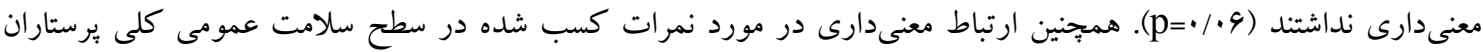

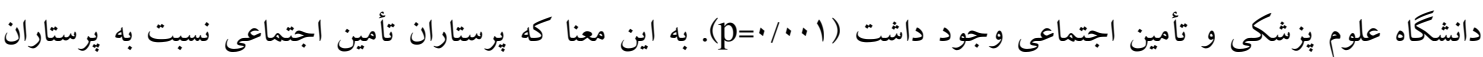

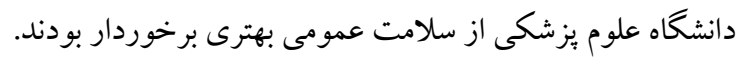

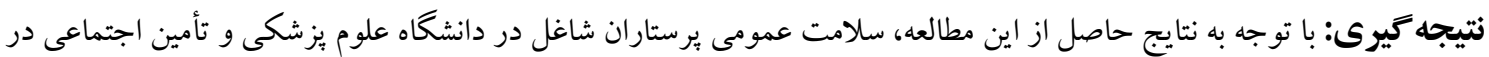

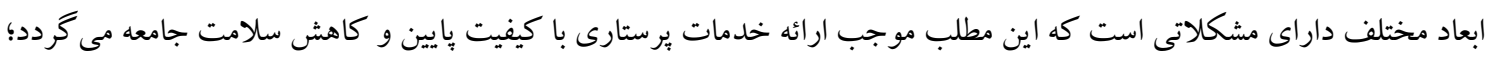

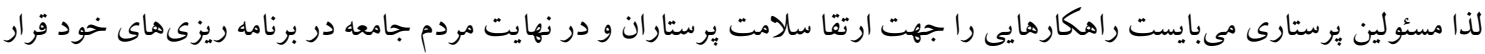


مشكلات مربوط به سلامت كسب كردهاند(1). مطالعهى

انجام شده در بيمارستانهاى دانشگاهى شهر تهران نشان داد

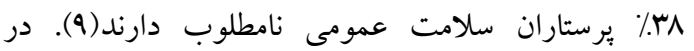
اصفهان F تا سا درصد برستاران دجار مشكلاتى در زمينه عملكرد اجتماعى بودهاند(·(1). در مطالعهى ديخر مشخص

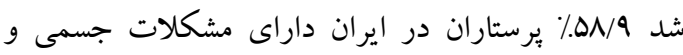

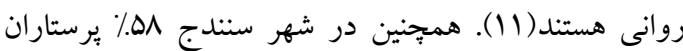
دجار افسردگى هستند(YI). به لحاظ اينكه بِرستاران به طور مستقيم و نزديكك با همدى اقشار اجتماع در ارتباط هستند، مسئوليت آنها در قبال سلامت و زندگى افراد دو جندان

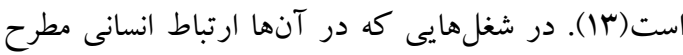
است تنيدگى بيشترى وجود دارد و باعث به مخاطره انداختن

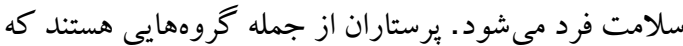
بيشترين استرس شغلى را تجربه مى كنند. استرس شغلى يكك بِديده جند بعدى و مخرب بوده كه مىتواند موجب افزايش غيبت و كاهش انرزى و بازده كارى شود كه منجر به افت كيفيت مراقبت از بيمارمىشود(f). عوامل استرسزاى شغلى متعددى در حرفه برستارى وجود دارند كه از جمله اين عوامل مىتوان به كار در نوبت كارى، فشار كارى، تعارض با همكاران، تماس مكرر با رنج و مركى بيماران، كمبود منابع حمايتى و كمبود وقت براى رسيدگى به به بهان

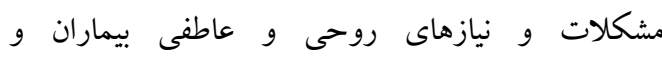

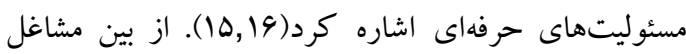
بيمارستان، برستارى از شغلهايى است كه فرد ساعات

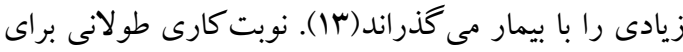

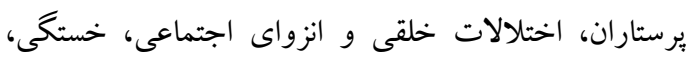
عصبانيت، افسردگى و اضطر اب را به همراه دارد(IV). كار طولانى با بيماران بدحال، و ايفاى نقش حمايتى بيماران

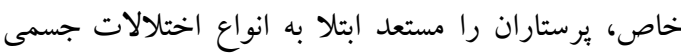

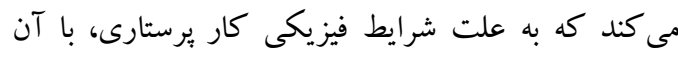

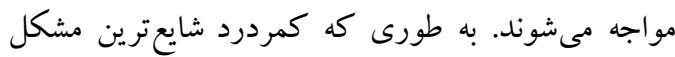
جسمى بيش از نيمى از زنان برستار است كه باعث

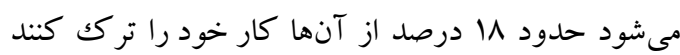

سازمان بهداشت جهانى سلامتى را رفاه كامل جسمى، روانى، اجتماعى و نه تنها بيمارى يا معلول نبودن دانسته و در سالهاى اخير توانائى داشتن يكك زندگى اقتصادى و جتماعى مثمر را، به اين تعريف اضافه كرده است(1). سلامتى داراى ابعاد جسمى، روانى و اجتماعى است كه شرط لازم و ضرورى براى ايفاى نقشهاى فردى و

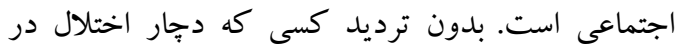

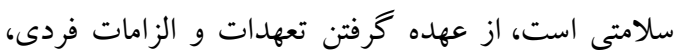
خانوادگى و اجتماعى ناتوان خواهد بود(Y). سازمان بهداشت جهانى فردى را كه احساس راحتى، احساس

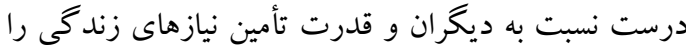
داشته باشد، سالم مىداند(ب). يكى از فاكتورهاى مؤثر بر سلامت عمومى شغل افراد است. برخى از مشاغل با قرار دادن فرد در معرض عوامل تنشزاى متعدد و مختلف فيزيكى، جسمى، روانشناختى و اجتماعى بيش از ساير

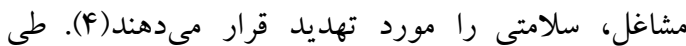
فر آيند اشتغال به كار، بهواسطه رويارويى كار كنان با عوامل گوناگون، سلامتى آنان در معرض خطر قرار خواهد گرفت هر קند همه مشاغل از تنشهاى مرتبط با محيط كار رنج مىبرند؛ اما اين مسئله در حرفه برستارى مشهودتر است(ه). يرستارى به عنوان يكى از جهار حرفه اول بر استرس دنيا

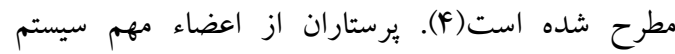
خدمات سلامت هستند كه جامعه بشرى به خدمات آنها نيازمند دارند؛ كه با ايفاى نقشهاى مختلف بر نظام

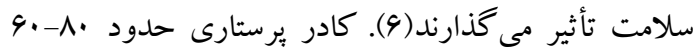
درصد نيروى انسانى بيمارستانها را تشكيل مىدهند. به

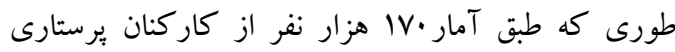
مرد و زن در بخش دولتى و خصوصى كشور مشغول به كار مىباشند(V). سازمان بهداشت جهانى پس از مطالعه بر

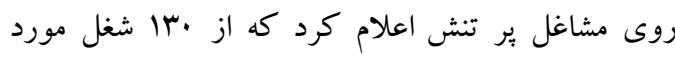

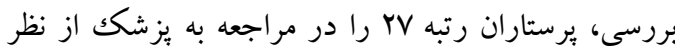


مطالعات فوق بيانكر اين واقعيت تلخ است كه برستاران در كشورهاى مختلف و ايران در معرض آسيب قرار دارند همجنين در مصاحبهاى كه با برستاران در شهر سنتدج انجام شد اين مشكل در آنان نيز به درجاتى وجود داشت؛ بنابر اين برسات

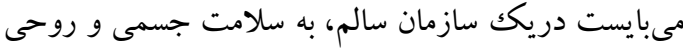
كاركنان به همان اندازه كه به توليد و بهرهورى تأكيد مىشود، توجه شود. لذا اهميت سلامت برستاران به عنوان عضو اصلى سيستم سلامت كشور كه وظيفه حفظ سلامت خود، خانواده و جامعه را بر عهله دارند، امرى حياتى و ضرورى است و توجه مسئولين بهداشت و درمان به عوامل

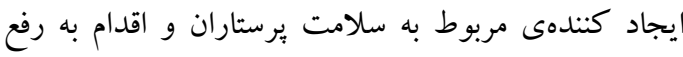

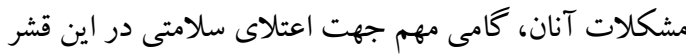
خواهد شد. لذا اين مطالعه، با هدف مقايسه سطح سلامت عمومى يرستاران شاغل در بيمارستان هاى آموزشى دانشگاه

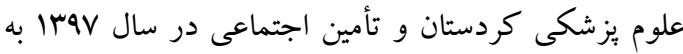

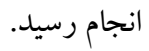

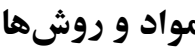

اين مطالعه به صورت مقطعى توصيفى -تحليلى بود. كليه برستاران شاغل در بيمارستانهاى وابسته به دانشكاه و بيمارستان تأمين اجتماعى جامعه مورد مطالعه را تشكيل

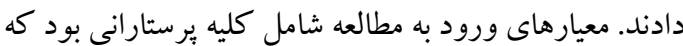
بهصورت قراردادى، آزمايشى، بيمانى و قطعى مشغول به فعاليت بودند و حداقل يكك سال از اشتغال آنها در بالين

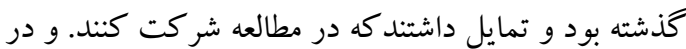
صورتى كه هر كدام از ملاككهاى بالا را نداشتند يا به بيمارى مزمنى مبتلا بودند كه به شغل آنان ارتباط نداشت از

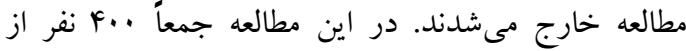
يرستاران انتخاب شدند جون در بيمارستان تأمين اجتماعى

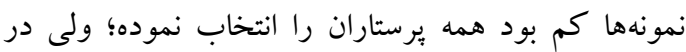

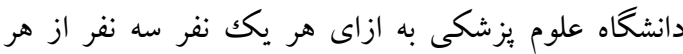

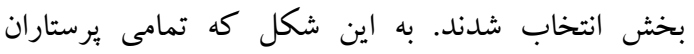

و يا به مشاغل ديخر روى بياورند همجنين اختلالات خواب و ريتمهاى بيولوزيكك از جمله مشكلاتى است كه به وفور در ميان اين قشر يافت مىشود(·). برستارانى كه از سلامت عمومى خوبى برخوردار نيستند، قادر نخو اهند بود كه مراقبتهاى مؤثرى از بيماران انجام دهند كه اين مسئله خطر اشتباهات و بروز حوادث شغلى را افزايش مىدهد كه مها در نهايت عواقب آن هم متوجه بيمار و هم برستار خواهد

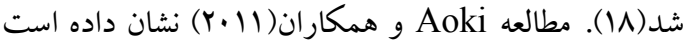
وجود استرس در يرستاران باعث فرار از شغل, برخورد ميان كاركنان، آسيب يذيرى در ارتباطات حرفه اى و در نهايت نارضايتى و تركك شغل مىشود(^). مطالعهى بدرى زاده و همكاران (זوسا) بر روى يرستاران شاغل در بيمارستانهاى دولتى نشان داد كه هA درصد يُ ستاران اختلال در سلامت عمومى داشتند كه در بعد روابط اجتماعى بيشترين مشكل را داشتند(19). مطالعه Aiazzam و همكاران (Y.IV) نيز نشان داد كه تعارض در محيط كار و نارضايتى شغلى بر روى كاركرد اجتماعى و خانوادگى يرستاران تأثير

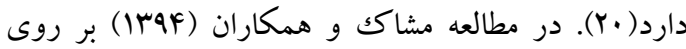
يرستاران مشخص شد كه برستاران از لحاظ جسمى بيشترين مشكل را داشته بودند( (Y)؛ و در مطالعهى خيرى و همكاران ئرسان

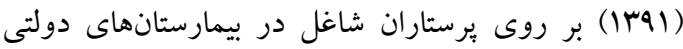

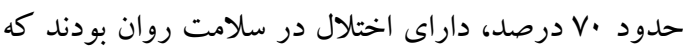
بيشترين اختلال در بعد تعاملات اجتماعى و كمترين مشكل

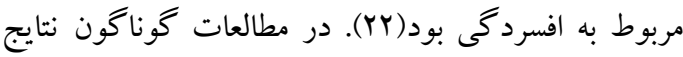
نشان داد كه ابعاد سلامت بِرستاران با درجاتى متفاوت دجار برار

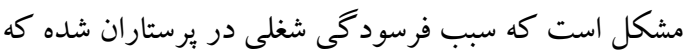

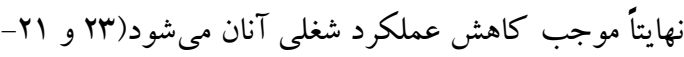

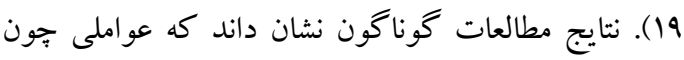

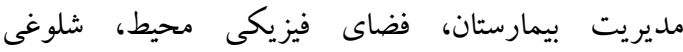
بيمارستانها، ميزان حقوق و در آمد، برداخت به موقع مزايا،

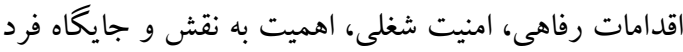
در سازمان و دادن بِاداش بر روى سلامت عمومى برستاران

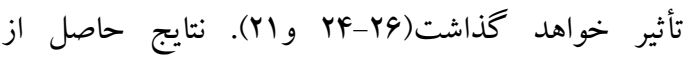


است. در مورد خرده مقياس مربوط به كاركرد اجتماعى، كسب نمره · تا ه نشانه سلامت كامل در برقرارى روابط بين فردى و كارى است. نمره ·1 تا ها نشانه آن است كه سلامت نسبى وجود دارد و كسب امتياز 19 تا ال نشانه اختلال شديد در روابط فردى و اجتماعى است. در مورد خرده مقياس مربوط به افسردگى و خود كشى، كسب نمره • تا و نشانه سلامت مطلوب، ·1 تا ها نشانه آن است كه كاه گاهى افسردگى به وجود مى آيد و 19 تا ال نشانه ابتلا

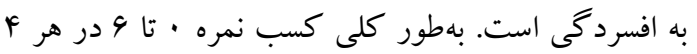
خرده مقياس نشانه آن است كه هيج مشكلى وجود ندارد كسب نمره V تا I| نشانه اختلال خفيف، نمره Y I تا 19 اختلال متوسط و نمره VV تا اY اختلال شديد است. در مورد نمره سلامت عمومى بهطور كلى · تا Y Y نشانه سلامت

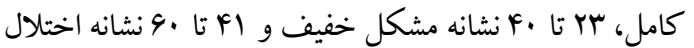
متوسط و ا9 تا AF نشانه مشكل شديد است...مطالعات متعدد ضريب پايانى تست را با استفاده از روشهاى باز آزمايى

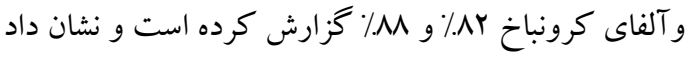
حساسيت و ويثز گى اين برسشنامه در بهترين نقطه برش(سب) به ترتيب سهو و Y در صد بود(IV, rV (I). با توجه به مطالعات كوناگون و نتايج مشابه، نقطه برش سلامت عموى در يُزوهش حاضر هم r در نظر گرفته شد. نمره بالاتر از سY نشانه اختلال و كمتر از سب نشانه سلامت است. و در خصوص خرده مقياس ها هم نقطه برش 9 در نظر كرفته شد. به اين صورت كه نمره كمتر از 4 نشانه عدم مشكل و بالاتر از V به عنوان اختلال در زير مقياس مورد نظر در نظر بود. در پپايان داده ها وارد محيط SPSS با نسخه سr شد و سيس با توجه به اينكه همه ابعاد كيفى بودند با كمكك آزمون آمارى كاى اسكور و تى تست مورد تحليل قرار كرفتند. در اين مطالعه به واحدهاى مورد مطالعه اطمينان داده شد كه به آنان آسيبى وارد نخواهد شد و در صورت تمايل مىتوانند از مطالعه خارج شوند و در طول مطالعه با آنان با احترام برخورد شد و به آنان يادآورى شد كه اين

$$
\text { مطالعه به نفع آنان است. }
$$

بيمارستان تأمين اجتماعى (·. (1 نفر) و در بيمارستانهاى وابسته به دانشگاه ... نفر بهصورت طبقهاى تصادفى از بخش هاى داخلى، جراحى، ويزه، اورزانس، كود كان وزنان انتخاب شدند (اين بخشها در بيمارستان تأمين اجتماعى موجود بودند). در يايان نمونهها به لحاظ همسان بودن ارزيابى شدند. ابزار گردآورى دادهها بيرسشنامه بود كه بخش اول آن شامل مشخصات فردى :برستاران بود كه اطلاعات فردى مانند سن، جنس، وضعيت تأهل، تعداد فرزندان، نوع استخدام، سابقه كار، نوع بخش و سطح تحصيلات را شامل بود. بخش دوم يرسشنامه شامل برسشنامه General Health ) سؤالى سلامت عمومى Y بود كه براى اولين بار توسط گلدبر گ Questionnaire در سال 19VD ساخته شده است؛ كه داراى f مقياس درجهاى ليكرت است و هر مقياس V سؤال دارد كه نمره هر سؤال بلصورت (·-1-r-r) محاسبه مىشود. فقط در

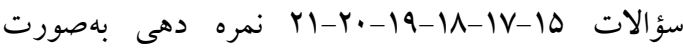
عكس است. در اين برسشنامه جهار گرووه از اختلالات غير سايكو تيكك شامل: نشانگان جسمى با سؤالات ا تا V، اختلال

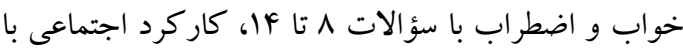
سؤالات ها تا الب و افسردگى و ميل به خود كشى با سؤالات

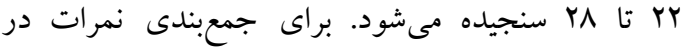

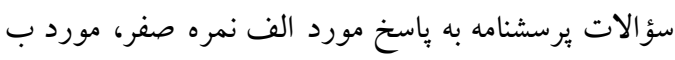
نمره يك، مورد ج نمره دو و مورد د نمره سه تعلق مى گيرد. در هر خرده مقياس از نمره 9 به بالا و در مجموع برسشنامه از نمره r ب به بالا بيانگر علائم مرضى است. در مورد خرده مقياسها به ترتيب در مورد مقياس جسمانى كسب نمره · تا 9 نشانه سلامت جسمانى، · ل تا ها سلامت متوسط و 19 تا ا انشانه شدت علائم جسمانى بوده و نياز به مراجعه به متخصص است. در مورد خرده مقياس مربوط به اضطر اب و اختلال خواب، كسب نمره · تا 9 نشانه سلامت مطلوب، .1 تا ها نشانه آن است كه كاه گاهى اضطراب به وجود مى آيد و 19 تا ال اضطر اب شديد و نياز

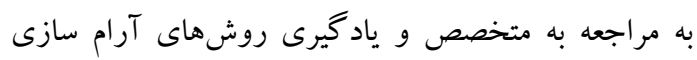


تأمين اجتماعى 9\% آنان افسردگى شديد داشتند. آزمون

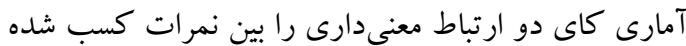
در Fا بعد وضعيت سلامت عمومى برستاران دانشگاه علوم

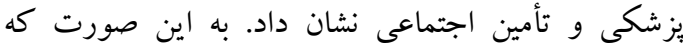

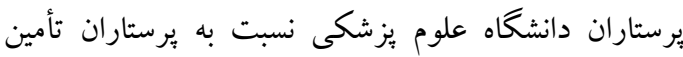
اجتماعى در Y بعد جسمانى و روابط بين فردى و اجتماعى از سلامت كمترى برخوردار بودند و برستاران شاغل در إنافي

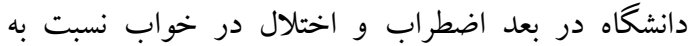
برستاران تأمين اجتماعى از سلامت بالاترى برخوردار بودند

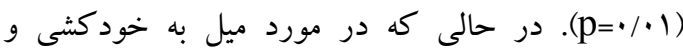

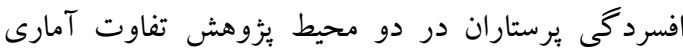

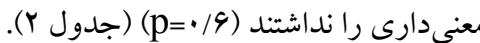
نتايج به دست آمده در مورد سلامت عمومى كلى برستار إندان

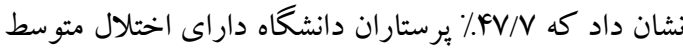
در حالى كه در تأمين اجتماعى بَّ٪ داراى اختلال متوسط

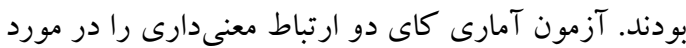
نمرات كسب شده در سطح سلامت عمومى كلى بين

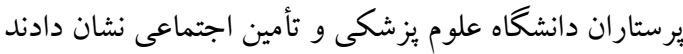

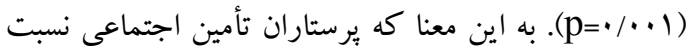

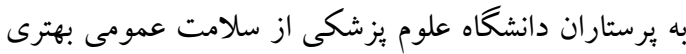

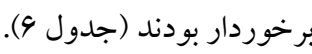

يافته ها

نتايج نشان داد كه ميانخين سنى واحدهاى مورد مطالعه در

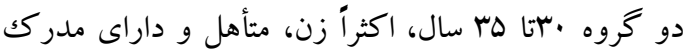
كارشناسى بوده و بهصورت نوبت در كردش مشغول بكار بودند؛ اما اكثر برستاران شاغل در دانشگاه در بخش داخلى

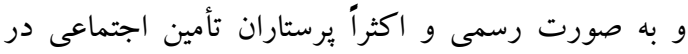
بخش اورزانس و به صورت رسمى آزمايشى مشغول به كار

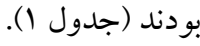
آزمون آمارى تى نشان داد كه بين دو محيط يُوهش از نظر تعداد فرزند و سابقه كارى اختلاف آمارى معنىدارى وجود

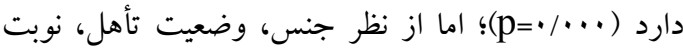
كارى و سطح تحصيلات اختلاف آمارى معنىدارى بين دو نور محيط يُروهش وجود نداشت (p=-19). در مورد F بعد وضعيت سلامت در برستاران شاغل در دو محيط يزوهش نتايج به تفكيك نشان داد كه در بعد وضعيت

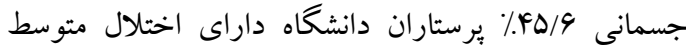
بودند؛ اما در بيمارستان تأمين اجتماعى آسا آنان اختلال

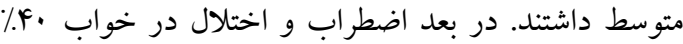

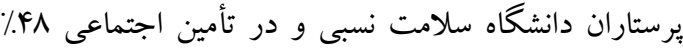
آنان سلامت نسبى داشتند. در بعد روابط فردى و اجتماعى

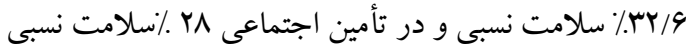
داشتند. در بعد افسردگى و ميل به خودكشى 11\% از يرستاران دانشكاه افسردگى شديد داشتند و در برستاران

جدول ا. توزيع فراوانى مشخصات فردى واحدهاى مورد مطالعه بر اساس اطلاعات فردى و شغلى

\begin{tabular}{|c|c|c|c|}
\hline \multicolumn{2}{|c|}{ محل اشتغال } & \multicolumn{2}{|c|}{ مشخصات فردى } \\
\hline تأمين اجتماعى & دانشگاه علوم يزشكى & & \\
\hline تعداد (درصد) & تعداد (درصد) & & \\
\hline אז(זr/\%) & $(\%, Y V / I) \wedge F$ & 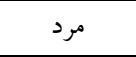 & جنس \\
\hline$(1.9 \mathrm{~V}) 9 \mathrm{~V}$ & $(\%$ ( V / 9 )r 19 & زن ان & \\
\hline ( & (\%/rY)৭৭ & مجرد & وضعيت تأهل \\
\hline$(\% \Delta \cdot) \Delta$. & $(\%$ (.91) IA & متأهل & \\
\hline$(\% 10) 10$ & $(\% \mathrm{~V}) \mathrm{YI}$ & مطلقه و بيوه & \\
\hline$(1.9 \pi) 9 \pi$ & $(\%$ ( VD)YYQ & كارشناس & ميز ان تحصيلات \\
\hline
\end{tabular}




\begin{tabular}{|c|c|c|c|}
\hline$(\% I r \mid r$ & $(\%$ (I) & كارشناس ارشد و بالاتر & \\
\hline$(\% r \Delta) r \Delta$ & $(\%, r) r q$ & كارشناس ارشد و يَايين تر & \\
\hline$(\% q q) r q$ & $(\% / r \cdot) 9$ & رسمى قطعى & \multirow[t]{5}{*}{ وضعيت استخدامى } \\
\hline$(\% \mathrm{IV}) \backslash \mathrm{V}$ & $(\%$ YA)AF & رسمى آزمايشى & \\
\hline$(\% 10) \backslash \Delta$ & $(\%$ (I) & بيمانى & \\
\hline$(\% \mathrm{IV}) \backslash \mathrm{V}$ & $(\%$.YY $) 99$ & قراردادى & \\
\hline$(\% / Y) \mid r$ & $(\% M) \Delta F$ & طرحى & \\
\hline$(\% \cdot) 1$. & $(\%$ ( & $r \Delta-r$. & \multirow[t]{4}{*}{ سن } \\
\hline$(\% . r \Delta) Y \Delta$ & $(\%$ (\%Y)99 & $r \cdot-r \Delta$ & \\
\hline 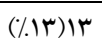 & $(\% / q q) \backslash F V$ & هי-r & \\
\hline$(\% \Delta r) \Delta r$ & $(\% \mid \mathrm{V}) \mathrm{DI}$ & 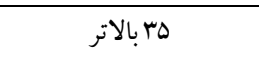 & \\
\hline$(\% \wedge \Lambda) \backslash \Lambda$ & $(\%$.Y9)VA & ثابت & \multirow{2}{*}{ نوبت كارى } \\
\hline$(\% / A Y) \Lambda Y$ & $(\%$ (\%)YYY & در گردش & \\
\hline 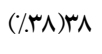 & $(\% 19) \Delta V$ & بدون فرزند & \multirow[t]{5}{*}{ تعداد فززندان } \\
\hline$(\% / 4 \cdot) 4$. & $(\% \mid \mathrm{V}) \Delta I$ & 1 & \\
\hline$(\% \mathrm{IV}) \mid \mathrm{V}$ & $(\% / q \cdot) \mid r$. & r & \\
\hline$(\% 1 \cdot) 1$. & $(\% 1 \cdot) r$. & $r$ & \\
\hline$(\% \Delta) \Delta$ & $(\% / 1 F) \& Y$ & F بالاتر & \\
\hline$(\% \mathrm{~V}) \mathrm{V}$ & (\% & $\Delta-1$ & \multirow[t]{4}{*}{ سابقه كارى } \\
\hline$(/ . \Delta q) \Delta q$ & $(\% \mathrm{rq}) \wedge \mathrm{V}$ & $1 \cdot-9$ & \\
\hline$(\%$ YF)YF & $(\% / r V) 111$ & $10-11$ & \\
\hline$(\% \cdot r \cdot) r$. & $(\%$ III) & بالاى 19 سال & \\
\hline$(\%$ (\%)IY & $(\% F \Lambda) \Delta F$ & داخلى & \multirow[t]{7}{*}{ بخش } \\
\hline$(\% 10) \backslash \Delta$ & $(\%$ ( & جراحى & \\
\hline$(\% / \Lambda) \wedge$ & $(\% V) Y I$ & ويثه & \\
\hline$(\% / Y) \mid r$ & $(\% \Delta) 10$ & كود كان & \\
\hline (\%IY)IY & $(\% / \Gamma) \Lambda$ & نورولوزى & \\
\hline$(\% \cdot r \cdot) r$. & $(\% 9) r$. & زنان & \\
\hline$(\% \mathrm{IV}) \backslash \mathrm{V}$ & $(\% 11 / \Gamma) \mu r$ & |ورزانس & \\
\hline
\end{tabular}

جدول r. تعيين و مقايسه سطح سلامت يرستاران شاغل در بيمار ستانهاى دانشكاه علوم يزشكى و تأمين اجتماعى بر اساس ابعاد سلامت

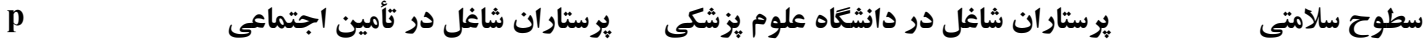

\begin{tabular}{|c|c|c|c|c|c|c|}
\hline \multirow[t]{5}{*}{$* \mathrm{p}=\cdot / \cdot$} & درصد & درصد & تعداد & تعداد & & وضعيت \\
\hline & $9 r$ & Gr & $\Delta \Lambda$ & $1 \ldots$ & سلامت كامل & جسمانى \\
\hline & YA & 1. & m & IrV & متوسط & \\
\hline & 1. & rA & 11 & $9 \pi$ & شديد & \\
\hline & $1 \ldots$ & $1 \ldots$ & $1 \cdots$ & $r .$. & جمع & \\
\hline
\end{tabular}


عاو براسى sقايسه ای سطح...

\begin{tabular}{|c|c|c|c|c|c|c|}
\hline \multirow[t]{4}{*}{$* \mathrm{p}=\cdot / \cdot$} & Mr & rr & $\mathrm{Fr} / 9$ & $1 Y \Lambda$ & سلامت كامل & \multirow{4}{*}{ 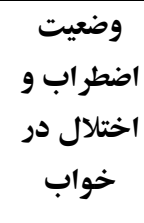 } \\
\hline & YN & rᄉ & f. & ir. & متوسط & \\
\hline & $r$. & $r$. & $I V / F$ & $\Delta r$ & شديد & \\
\hline & $1 \ldots$ & $1 \ldots$ & $1 \ldots$ & $\mu .$. & جمع & \\
\hline \multirow[t]{4}{*}{$* \mathrm{p}=\cdot / \cdot$} & 94 & 94 & 01 & lor & سلامت كامل & \multirow{4}{*}{ وضعيت } \\
\hline & YA & 1. & $r Y / 9$ & 91 & متوسط & \\
\hline & 1. & $r \Lambda$ & $19 / 4$ & $k q$ & شديد & \\
\hline & $1 \ldots$ & $1 \ldots$ & $1 \ldots$ & $r .$. & جمع & \\
\hline \multirow[t]{4}{*}{$\mathrm{p} \mathrm{p}=\cdot / \cdot$} & $v^{f}$ & $V_{f}$ & $\mathrm{VA}$ & MMF & سلامت كامل & \multirow{4}{*}{ خوضعيت } \\
\hline & $r$. & $r$. & If & FF & متوسط & \\
\hline & 9 & 9 & 11 & rr & شديد & \\
\hline & $1 \ldots$ & $1 \ldots$ & $1 \ldots$ & $r .$. & جمع & \\
\hline
\end{tabular}

جدول Г. تعيين و مقايسه سلامت عمومى كلى ثيرستاران شاغل در دانشكاه علوم يزشكى و تأمين اجتماعى

\begin{tabular}{|c|c|c|c|c|c|}
\hline \multirow[t]{2}{*}{ مقدارp } & \multicolumn{2}{|c|}{ يرستاران شاغل در تأمين اجتماعى } & \multicolumn{2}{|c|}{ يرستاران شاغل در دانشكاه } & \multirow[t]{2}{*}{ سلامت عمومى } \\
\hline & درصد & تعداد & درصد & تعداد & \\
\hline \multirow[t]{5}{*}{$\because \mathrm{p}=\cdot / \cdots$} & ro & ro & ro & VD & سلامت كامل \\
\hline & rV & rV & $19 / r$ & $\Delta \wedge$ & خفيف \\
\hline & rr & rr & $\mathrm{FV} / \mathrm{V}$ & let & متوسط \\
\hline & 4 & 9 & $\wedge$ & rF & شديد \\
\hline & $r .$. & $r .$. & $1 \ldots$ & $r .$. & جمع \\
\hline
\end{tabular}

يرستاران حدود ·1 سال سابقه كارى داشتند كه با سن آنـان

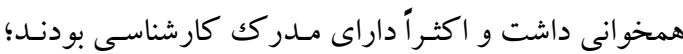
زيـرا در حـال حاضـر اكثريـت فـارغالتحصـيلان برسـتارى كارشناس هستند. - كاس بسين مشخصـات فـردى سـن، جـنس، سـطح تحصسيلات و نوبت كارى با سلامت عمـومى برستاران ارتبـاط معنى دارى لئن وجود نداشت. در مطالعه سبهر منش و همكاران (rarا) نيز

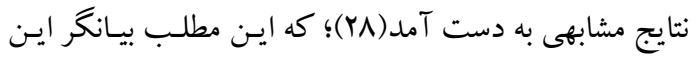
واقعيت است كـه اختلال در سـلامت عمـومى مسى توانـد در سـنين بـالاتر از ·r سـال و كمتـر نيـز ايجـاد شـود همجنـين

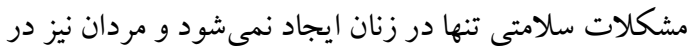

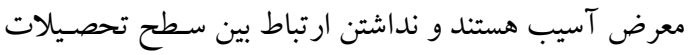

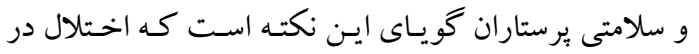

نتايج حاصل از اين مطالعه نشـان داد كه اكثريـت برستاران شاغل در واحدهاى مورد مطالعه در دانشكاه علوم يزشكلى و

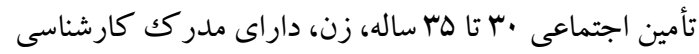

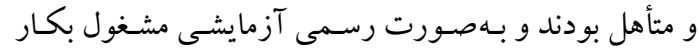
بودند. در مطالعه انجام شده توسط سـيـهر مـنش و همكـاران

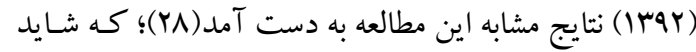

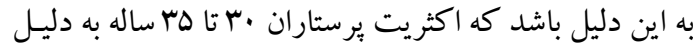
جوان بودن در مطالعه شر كت نمودهاند و برستاران ميانسال

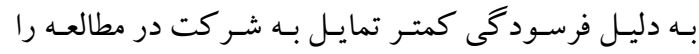

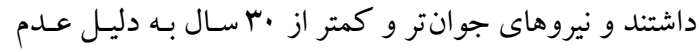
استخدام كمتر در مطالعه شر كت كردهاند؛ و جون بروس برستاران در اين رنج سنى بودند اكثريت متأهل بودند. همجنين بيشتر 
دليـل شــفتهـاى طـولانى، كـار سـخت و ســخين و سـريا ايستادنهاى زياد دجار انواع مشكلات جسمى خواهند شـد كه كمردرد شايع ترين نوع اختلال جسمى است كه موجب ستب تر كك كار در يرستاران مىشود. در بعـد اضطراب و اختلال

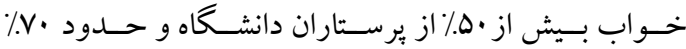

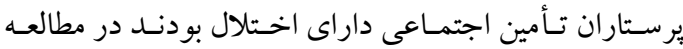
سبهر منش در مطالعه سبهر منش و همكاران (Y (Yr|) حسدود

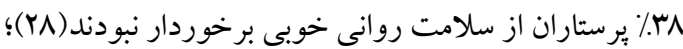

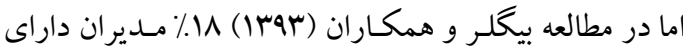

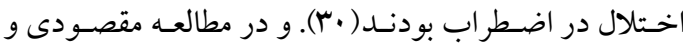
همكــاران (rar) ميـانكين اضـطر اب و اخـتلال در خـواب

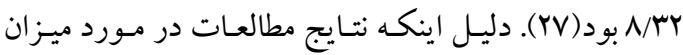

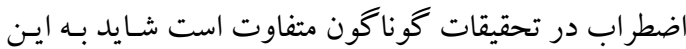

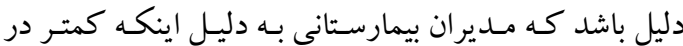

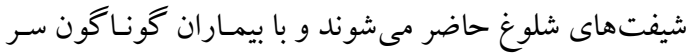

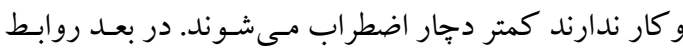
فردى و اجتماعى اهـ/ برستاران داراى سلامت كامـل و بكّ/ سلامت نسبى و 19٪ داراى اختلال شديد بودند در حالى كه

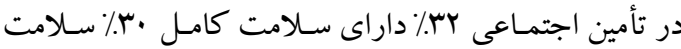

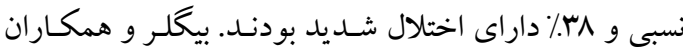

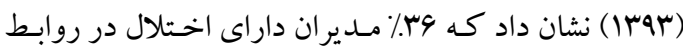
فردى بودند(Yq). در مطالعه مقصودى و همكاران (ITqF) ميانخين اختلال در روابط فردى و اجتماعى لا ٪ بـود(YV).

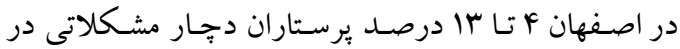
زمينه عملكرد اجتمـاعى بـوده انـد(Y) (I مطالعه ى ايزهـام و

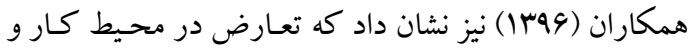

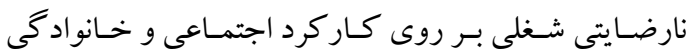

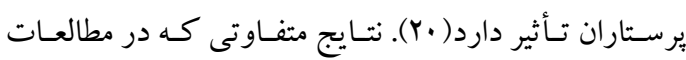
مختلف در مـورد اختـلال در روابـط فـردى و اجتمـاعى بـهـ

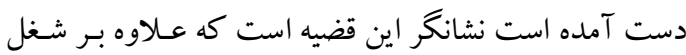

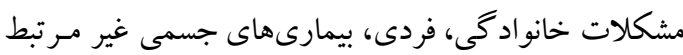

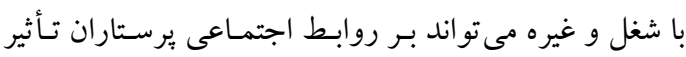

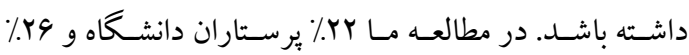

سلامتى با سطح تحصيلات مرتبط نيست جرا كه فشار كارى

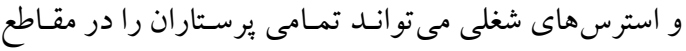
تحصيلى تحت فشار قرار دهد؛ اما از نظر وضعيت استخدامى بين دو گروه ارتباط آمارى معنىدارى وجـود داشـت و بين

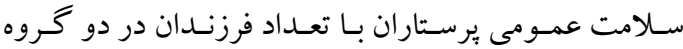
اختلاف معنىدارى وجود داشت يعنى هر جه تعداد فرزنـدان كمتر باشد يُرستاران از سـلامت عمـومى بـالاترى برخهوردار

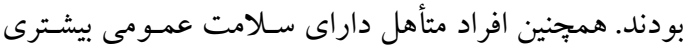
نسبت به افر اد مجرد بودند مقصودى و همكاران (Fسجا) نيز در مطالعه خود كه بر روى يرستاران شاغل در بيمارستانهاى رشت انجام داده بود نشان داد كه بين وضعيت استخدامى و

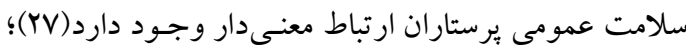
يعنى وضعيت سلامت عمومى برستاران رسـمى از طرحى و قراردادى بهتر بود. همجنين ميزان سابقهى كارى يرستاران بـا

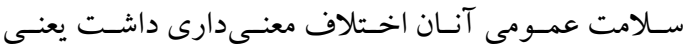

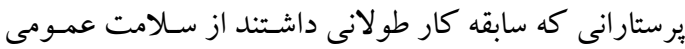
كمترى برخوردار بودند. در مورد اين نتايج مى توان خنين

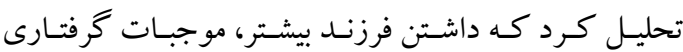
بيشترى را بـراى برستاران جهـت تربيـت و مر اقبـت از آنـان ايجاب مى كند كه همين نكته سبب عـدم توجه و مراقبـت يرستاران از خود مىشود در ضمن يرستاران مجرد بـه نسبت فيت

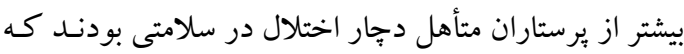

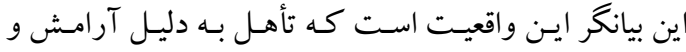

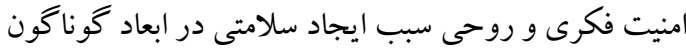

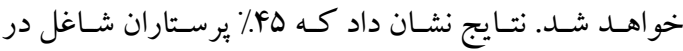

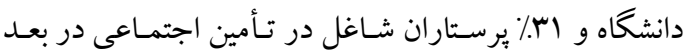

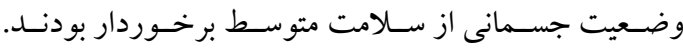

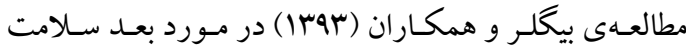
جسمانى نشـان داد كـه 99٪ درصـد مـديران بيمارستانى در

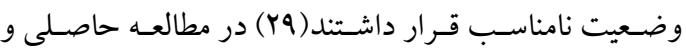
همكاران (rar|) كه در ميان كار كنان بيمارستانهاى شيراز انجام شد فراوانى اختلال هY درصد گزارش شده است( •r).

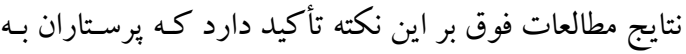


عملكرد شغلى آنان مىشود(rr و (Y-Y)؛ كه احتمالاً اين تناقض به دليل اين نكته است كه يُرستاران در محيط كـارى تـنش و مشكلات زيـادى را تجربـه خواهند كرد. همجنـين

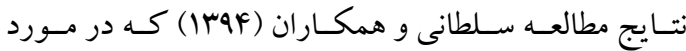
سلامت عمومى دانشجويان يرستارى انجام شده بود نشان داد كه سلامت عمومى كلى آنان در حد نرمال بود( (ب)؛؛ كه اين نتيجه دال بر اين دارد كه جـون دانشـويان هنوز در محيط كارى فعاليت خود را شروع نكردهانـد و مسئوليت حرفهاى ندارند از سلامت كامل برخوردار هستند. در نهايت تفاوت و شباهتهاى حاصل از اين مطالعه با مطالعات گونان مى تواند به دلايلى جون ميزان حمايت مديران از برستاران در محيط هاى كارى، ويزّى هاى فردى و خانوادگى برستاران، ميزان

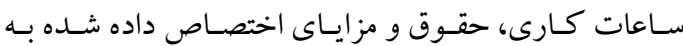
ير ستاران، ميزان تقدير و تشكر دست اندر كاران از يرستاران، وجود امكانات رفاهى و امنيت شغلى براى آنان باشد.

\section{نتيجه كيرى}

نتايج حاصل از ايـن مطالعه نشـان داد كه سـلامت عمـومى تئى

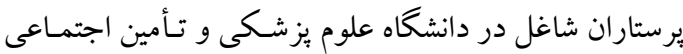

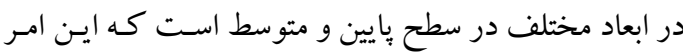

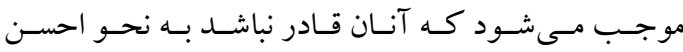
مر اقبت هاى موثر و با كيفيتى را براى بيماران انجام دهند كه

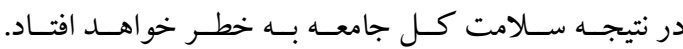
محدوديت هايى كهه در ايـن يـزوهش وجـود داشـت شـامل:

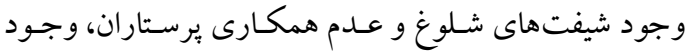

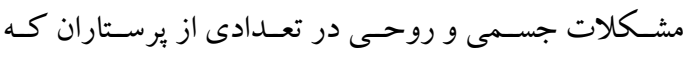

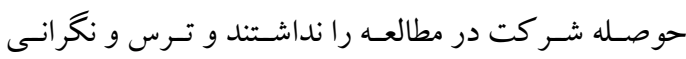
ير ســتاران آزمايشـى و بيمـانى از اينكـهـه در اسـتخدام آنـان

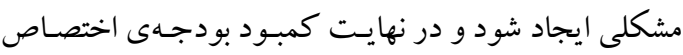
يافته به طرح را مىتوان برشمرد.

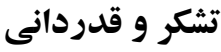

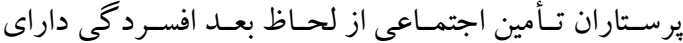
اختلال بودند. در مطالعه محمودى و همكاران (Yar|) ميزان

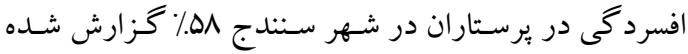

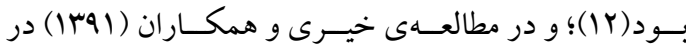

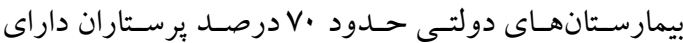
اختلال در سلامت روان بودند كه بيشترين اختلال در بعـد

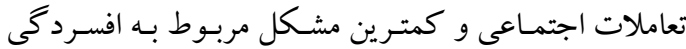

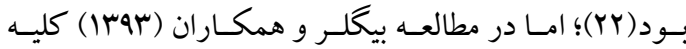

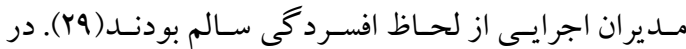

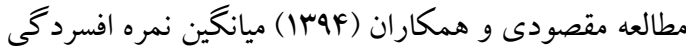

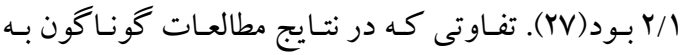
دست آمده نشان مىدهد كه يرستاران در محيط كارى خود با توجه به شرايط موجود وضعيت خانواد كى حمايت مديران

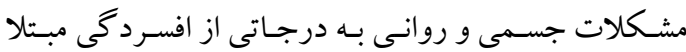

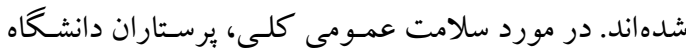

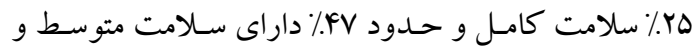

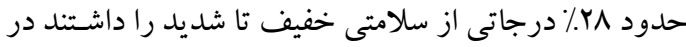
حالى كه در تأمين اجتماعى هَّ/ بر ستاران سـلامت كامـل و و

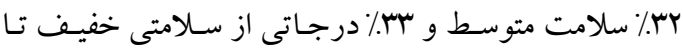

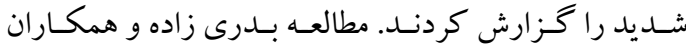

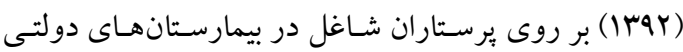

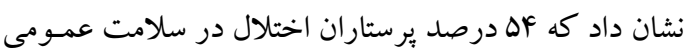

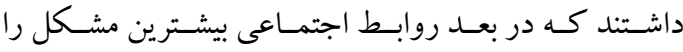

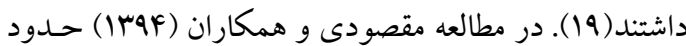

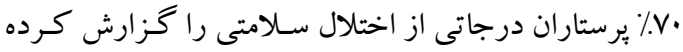

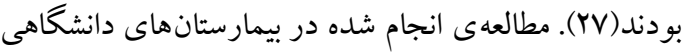

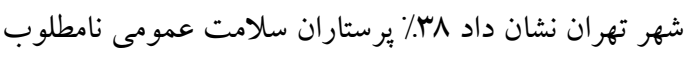

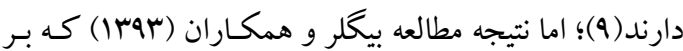
روى سلامت عمومى مديران اجر ايى انجام شـد نتـايج نشـان

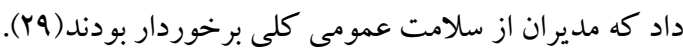

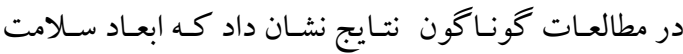

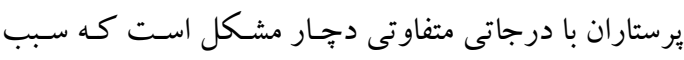

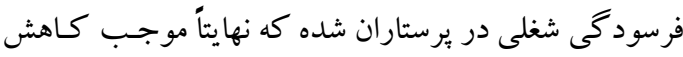




$$
\begin{aligned}
& \text { خـاطر حمايـت مـالى، شـوراى بزروهشى دانشـكده بـه دليـل } \\
& \text { ايـن مقاله حاصـل طـرح تحقيقـاتى مصـوب دانشـاه علـوم } \\
& \text { حمايت همه جانبه و كليه برستاران شـاغل در دانشـاه علـوم }
\end{aligned}
$$

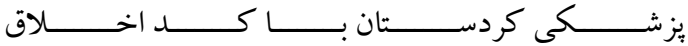

$$
\begin{aligned}
& \text { يز شكى و تامين اجتماعى تشكر و قدردانى مىشود. }
\end{aligned}
$$

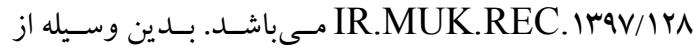

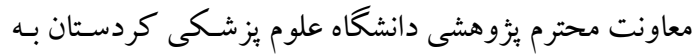

1.Eilderabadi S.Dabagie Community health nursing. 6nd.Tehran: Ghamehnegar publishing. 2015:23,56[ In Persian].

2.Cavanaugh C, Campbell J, Messing JT. A longitudinal study of the impact of cumulative violence victimization on comorbid posttraumatic stress and depression among female nurses and nursing personnel. Workplace Health Saf . 2014; 62(6):224-32.

3. Zarea S, SHahani N, Babaei Heydarabadi A, Asghari M, Aminizadeh R, Nazemorroaya V, et al. Investigation of the relationship between general health and works sleep quality and work Industries Go,Sirjan ,incidence in Gohar mineral. Journal of Ilam University of Medical Sciences 2013; 21(2):112-9[ In Persian].

4. Darvishpur kakhki A, Ebrahimi H, Alavi majd H. Health status of nurses of Hospitals Dependent to Shahroud Medical university. IJN. 2009;22(60):19-27[ In Persian].

5.Amin-Khandaghi M, Pakmehr H. The relationship between students' critical thinking and mental health in Mashhad University of Medical Sciences. J Fund Ment Health.2011; 13(2):114-23. [ In Persian].

6. Shakerian A. The role of personality trait dimensions and gender on predicting marital adjustment. Journal of Kermanshah University of Medical Sciences. 2012 ; 15;16(1):16-22[ In Persian].

7. Hojjati H, Taheri N, Sharifnia SH. Mental health and physical health of nurses working night at Hospital of golestan University of Medical Sciences in 87-88 . Journal of Nursing \& obstric of Oromieh.2010;8(3):144-149[ In Persian].

8. Aoki M ,Keiwkarmka B .Job stress among nurses in public hospital .J Pub Health Dev ,2011;9 (1):19-27.

9. Arsalani N, Fallahi-Khoshknab M, Josephson M, Lagerstrom M. Iranian nursing staff's selfreported general and mental health related to working conditions and family situation. Int Nurs Rev. 2012; . 2012;59(3):416-23 [ In Persian].

10. - Mehrabi T, GHazavi Z. Health assessment of female nurses of Isfahan university of Medical Science. journal of hygiene and health.2003;2(1):1-5[ In Persian].

11.Mardani Hamooleh M, Shahraky Vahed A, Ebrahimi E. Mental Health Status of Nursing Staff. IJN. 2012; 24 (74) :28-35. [In Persian].

12.Mahmodi S, Zehni K. The comparison of depression prevalence between shift work nurses in education hospitals of Kurdistan medical sciences university. IJNR. 2013; 8 (1) :29-38[In Persian].

13. Pourreza A, Monazam M R, Abassinia M, Asghari M, Safari H, Sorani M et al . Relationship between job burnout and mental health of nurses working in province of Qom . jhosp. 2012; 11 (2) :45-54.

14. Rahmani F ,Behshid M,Zamanzadeh V. Relationnship between general health occupational steers and bum out in critical care nurses of Tabriz teaching hospital .Iran JNurse 2010; 23(66):55-62[ In Persian].

15. Zamanian Ardakani Z, Kakooei H, Ayattollahi M, Karimian S, Nasle Seraji G. Mental Health Survey on Shift Work Nurses in Shiraz Province, Iran. sjsph. 2008; 5 (4) :47-54 [ In

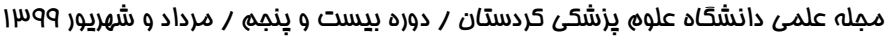


Persian].

16. Hansen N, Sverke M, Na"swall K. Predicting nurse burnout from demands and resources in three acute care hospitals under different forms of ownership: A cross-sectional questionnaire survey. IJNS 2009; 46: 96 107[ In Persian].

17. Mohamed Z, Newton JM, McKenna L. Belongingness in the workplace: a study of Malaysian nurses' experiences. Int Nurs Rev. 2014;61(1):124-30. [ In Persian].

18. Hojjati H, Taheri N, Sharifnia SH. Mental health and physical health of nurses working night at Hospital of golestan University of Medical Sciences in 87-88.J of Nursing \& obstric of oromieh.2010;8(3):144-149[ In Persian].

19.Badrizadeh A ,Farhadi A,Tarahi MJ,Saki M,Biranvand GH. Mental Health Status of Nurses in Governmental Hospitals of Khorramabad. Journal of Lorestan University of Medical Sciences.2013 15(3):62-69[ In Persian].

20. Aiazzam M , Abualrub RF, Nazzal AH. The Relationship Between Work-Family Conflict and Job Satisfaction Among Hospital Nurses. Nurs Forum. 2017;52(4):278-288.

21. Mashak B, Farhand B, Moghadam S, Pazhoom Z, Hajalikhani T, Taghipoor N, et al . Relationship Between Job Stress Among Nurses with Their General Health Status in Kamali Hospital in 1392. aumj. 2015; 4 (4) :231-236 [ In Persian].

22. Kheyri F, Seyedfatemi N, Oskouei F, Mardani-Hamooleh M. Nurses' mental health in Iran: A national survey in teaching hospitals. SJKU. 2017; 22 (4) :91-100 [ In Persian].

23. Paul Ratanasiripong*. Mental health of muslim nursing students in Thailand. ISRN Nurs. 2012;2012:463471.

24.Rahmani F,Behshid M. The Relationship between general health occupational Stress Burnout in critical nurses of Tabriz teaching hospital . IJN. 2010; 23 (66) :54-63 2010 :23(66):55-62[ In Persian].

25. Sahebazzamani M, Safavi M, Farahani.H. Burnout of nurses employed at Tehran psychiatric hospitals and its relation with social supports .Medical Science. 2009; 19(3): 206211.

26.Habibi R, Zahedifar F,Hadizadeh M,Ghobadi m,Mohamadi m. The Relationship between Job Stress, Depression in Operating Room Nurses in Shahid Rajaee Hospitals and Social Security in Qazvin in 2012. Scientific Journal of Arak. 2014 ;9(35):45-49[ In Persian].

27. Maghsoodi SH, Hssabi M,Emamisigarodie H,KazemnezhadL E,Monfared A. General health and its related factors in nurses working in educational centers of the city. Rasht .Journal of Nursing and Midwifery.2015;75(25):63-72 [ In Persian].

28.Sepehrmanesh Z,Ahmadvand A, Moraveji A,Mirzadeh M. Mental health of nurses in psychiatric and dialysis departments of Akhavan Hospital of Kashan University of Medical Sciences. Journal of Rafsanjan University of Medical Sciences.2009;12(1):31-41[ In Persian]. 29. Biglar M, Hayati Y, Rahmani H, Rajabnezhad Z, Dargahi H. Study Of General Health Among Tehran University Of Medical Sciences Hospital's Administrators. payavard. 2014; '8(1)':13-24 [ In Persian].

30. .Haseli N, Ghahremani L \& Nazari M. General health status and its related factors in the nurses working in the educational status and its related factors in the hospitals of Shiraz university of medical sciences, Shiraz, Iran. Nursing and Midwifery Studies 2013; 1(3): 14651[Article in Persian].

31.Soltani N. General Health Status of Nursing Students in AJA University of Medical Sciences. 2016; 2(4): 191-196[ In Persian]. 